products, that is, even with direct evacuation the gases are evolved too rapidly to be removed. For this reason most effort has been concentrated on slow runs, at temperatures below $60^{\circ} \mathrm{C}$; this, of course, also minimizes any errors arising from self-cooling. It should be noted that the lowest temperature at which this reaction previously appears to have been studied is $72^{\circ} \mathrm{C}$ (ref. 2).

Boldyrev and Eroshkin ${ }^{3}$ have recently observed similar behaviour when silver nitrite is irradiated wiht $\mathrm{X}$-rays before decomposition $\left(80^{\circ} \mathrm{C}\right)$. Their results show an inversion effect, that is, at higher doses the rate increases relative to lower doses. This behaviour was not observed in our work. Their inversion effect occurs at a relatively low level of inhibition when compared with the more marked inhibitory effects observed in the present data. Because this reaction is sensitive to the presence of gaseous products both during the irradiation and the subsequent thermal decomposition, we suggest that the inversion which they observed is an experimental artefact and may result from inhibition by gaseous products.

This investigation was supported in part by a US Public Health Service fellowship from the National Institute of General Medical Sciences to J.W. S. We gratefully acknowledge the co-operation of Dr. D. J. Smith in the use of the cobalt-60 source.

JoHN W. SchNeller

Ted B. Flanagan

Department of Chemistry,

University of Vermont,

Burlington, Vermont.

Received June 12, 1967.

${ }^{1}$ Sce, for example, Prout, E. G., and Herley, P. J., J. Phys. Chem., 66, 961 (1962).

${ }^{2}$ Boldyrev, V. V., and Eroshkin, V. I., Zhur. Vses. Khim. Ob-va im. Mendeleeva, 9, 704 (1964)

${ }^{3}$ Boldyrev, V. V., and Eroshkin, V. I., Russ. J. Phys. Chem., 40, 1 (1966).

\section{Solubility of Cupric Oxide in Pure Water at Temperatures up to $550^{\circ} \mathrm{C}$}

WE report here work in progress on the measurement of the solubility of metals and metal oxides in pure water, in the temperature range $50^{\circ}-550^{\circ} \mathrm{C}$ and at pressures up to 400 bars. The isobaric solubility of eupric oxide at 310 bars is reported here and compared with the 300 bar isobar for silica (quartz).

The solubility measurements were made by passing demineralized, distilled and de-aerated water, at the required temperature and pressure, through a packed bed of solute particles contained in an autoclave. To prevent carry-over of particulate material, the solution leaving tho autoclave was filtered through a stainless steel frit ( $1 \mu \mathrm{m}$ pore diameter). It was then cooled at pressure to reduce deposition in the cooling system and passed through a back-pressure regulator to be collected for analysis. The high pressure water eircuit was constructed from 'Nimonic' $80 A$ and 90 alloys. For the cupric oxidewater system the samples of solution were collected in dilute hydrochloric acid and were analysed for copper by the solvent extraction-colorimetric method described by Wilson ${ }^{1}$. The random error of the solubility values reported is about \pm 5 per cent, but this excludes the systematic orror resulting from the deposition of copper in the sampling system. It has been shown, however, that deposition was only significant at the highest solubility values, above $400 \mu \mathrm{g}$ copper $/ \mathrm{kg}$. No dependence of solubility on the rate of flow through the autoclave was found at rates from 1-12 kg water per hour, indicating that solutions leaving the autoclave were saturated.

Pocock and Stewart ${ }^{2}$ have also measured the solubility of copper, cuprous and cupric oxides in water in the temperature range $480^{\circ}-620^{\circ} \mathrm{C}$, but their results are almost an order of magnitude lower than those presented hore. It is suggested that this discrepancy may result from:

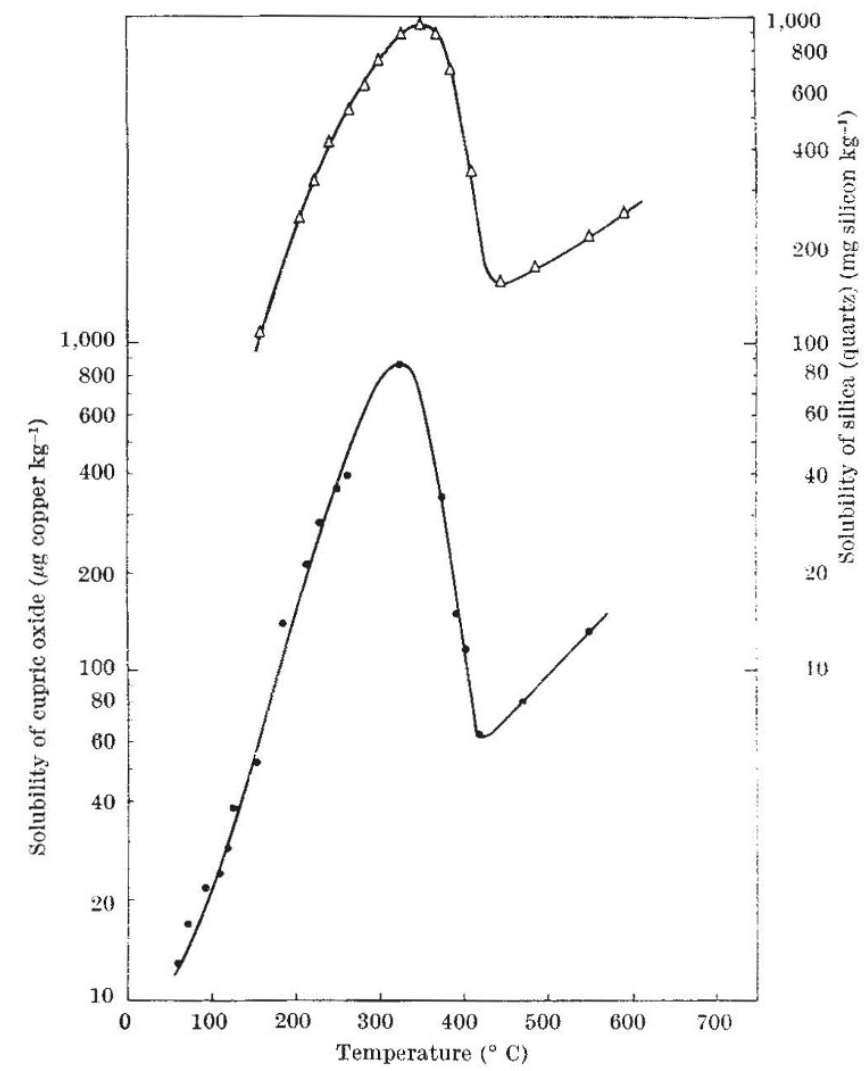

Fig. 1. Isobaric solubility of eupric oxide and silica in water. Present results with cupric oxide at 310 bars; $\triangle$, Heitmann's results ${ }^{3}$ with
silica at 300 bars.

(a) incomplete acid cleaning of their sampling system; (b) insufficient equilibration time in the solubility autoclave; (c) interaction with the high concentrations of iron in the water, which resulted from their use of stainless steel equipment; $(d)$ interaction with the hydrogen evolved during the corrosion of the stainless steel system.

The isobaric solubility of cupric oxide in water $(p \mathrm{H} 7 \cdot 5)$ at 310 bars obtained in the present work is shown in Fig. 1, which also shows the 300 bar isobar for the silica (quartz) water system ${ }^{3}$. The two curves show a markedly similar variation of solubility with temperature, with the silica solubilities about three orders of magnitude greater than those of cupric oxide. This similarity suggests that the nature of the solvent determines the isobaric temperature coefficient of solubility for systems of this type, while the nature of the solute determines the absolute solubility level. It follows therefore that a generalized solubility equation based on the physical properties of the solvent is feasible. Attempts to formulate such an equation, for example by Martynova ${ }^{4}$, have included only the specific volume of the solvent and have not successfully correlated the experimental data for any given system. Work is in progress in this laboratory on an empirical equation which includes further physical properties of wator.

\section{A. HAYward \\ B. HEARN \\ M. R. HUNT}

Physical Chemistry Section,

Central Electricity Research Laboratories,

Leatherhead, Surrey.

Received June 23, 1967.

${ }^{1}$ Wilson, A. L., A nalyst, 87 , 884 (1962).

${ }^{2}$ Pocock, F. J., and Stewart, J. F., Trans. Amer. Soc. Mech. Eing., 85, 33 (1963).

${ }^{3}$ Heitmann, H. G., Chemiker Ztg., 88 (22), 891 (1964)

4 Martynova, O. I., Russ. J. Phys. Chem., 587 (1964). 